We conducted a telephone survey of facilities for treatment of patients with comorbidity in such services. Ten residential rehabilitation addiction services were contacted and admission staff questioned on their attitudes to new referrals who were on medication for comorbid psychiatric disorders. The therapeutic orientation ranged from a therapeutic community to a skills-based programme; half were based on the abstinence 12-step approach. Only one of the 10 had psychiatric input and two had general practitioner support. The other seven could call on general practitioner services when necessary. Six would not accept patients on hypnotics, anxiolytics or antidepressants; the other four would work towards the reduction of such medication. Six would accept patients on antipsychotics, four refused. Five would accept patients on mood stabilisation, five refused. All would accept referrals on anti-epileptic medication.

We also asked about attitudes to medication prescribed to help maintain abstinence. Only two of the 10 would accept clients taking acamprosate calcium or naltrexone.

Poor outcome is associated with the failure to identify and address comorbid psychiatric disorders in patients with substance use disorders. Such patients would benefit from long-term residential rehabilitation. However, this is made difficult as many rehabilitation units refuse to take patients on medication. In addition, patients may be denied the benefits of new pharmacological treatments for addiction to reduce cravings, such as acamprosate calcium and naltrexone.

Hall, W. \& Farrell, M. (1997) Comorbidity of mental disorders with substance misuse. British journal of Psychiatry. I7I. 4-5.

Regier, D. A., Farmer, M. E. Rae, D. S., et ol (1990) Comorbidity of mental disorders with alcohol and other drug abuse: results from the Epidemiologic Catchment Area (ECA) Study. Journal of the American Medical Associotion. 264. 2511-2518.

Francis Keaney, Helen Crimlisk, Jenny Bearn Wickham Park House, Bethlem Royal Hospital. Monks Orchard Road, Beckenham, Kent BR3 3BX

Sir: Hall \& Farrell (1997) propose that the SCL-90 questionnaire could be used to detect probable anxiety and depressive disorders among drug-dependent persons. However, we think precaution is necessary.
We assessed the SCL-90 (Derogatis, 1994) in a Dutch population $(n=56)$ of drug-dependent persons who have entered a clinical treatment to screen for psychopathology. The first assessment took place in a pre-detoxification intake, the second assessment took place after detoxification. Results show that all sub-scales of the SCL-90 (with the exception of the hostility scale) decrease substantially (total score diminished $18 \%$ ), suggesting that high predetoxification scores may represent drugrelated symptoms, rather than psychiatric disorders. Furthermore, in another study we found that the validity of the SCL-90 to screen for DSM-III anxiety disorders is limited. Typically, satisfactory sensitivity was accompanied by low specificity (Hendriks, 1990).

We agree with the authors that the recognition and treatment of people with comorbid mental and substance use disorders is necessary. Also, staff in addiction services should be trained to identify anxiety and affective disorders in this population. However, before implementing instruments to detect psychopathology in drug-dependent patients, thorough investigation of the psychometric properties is necessary in this specific population, in particular given the potentially druginduced nature of the reported symptoms.

Derogatis, L. R. (1994) The Symptom Checklist 90-R: Administration, Scoring, and Procedures Manual (3rd edn). Minneapolis, MN: National Computer Systems.

Hall, W. \& Farrell, M. (1997) Comorbidity of mental disorders with substance misuse. British journal of Psychiotry. I7I. 4-5.

Hendriks, V. M. (1990) Addiction and Psychopathology: A Multidimensional Approach to Clinical Proctice. Rotterdam: Erasmus University.

I. H. A. Franken, V. M. Hendriks Research Department, Psychiatric Centre Bloemendaal, PO Box 53002. 2505 AA The Hague. The Netherlands

\section{Eosinophilia, agranulocytosis and clozapine}

Sir: There has been controversy in the Journal recently about the relationship between eosinophilia and clozapineinduced agranulocytosis (Amital et al, 1997; Bailey et al, 1997). Evidence on the predictive value of eosinophilia for subsequent emergence of neutropenia and/ or agranulocytosis in clozapine-treated patients is not robust (Hummer et al,
1996; Ames et al, 1996). Undue concern about the emergence of agranulocytosis may lead to discontinuation of clozapine which may have significant impact on the future course of the disease.

A 22-year-old White male with a twoyear history of paranoid schizophrenia with recurrent suicidal ideas was started on clozapine after he failed successive trials with thiothixene, haloperidol, and risperidone. The clozapine dose was gradually increased to $400 \mathrm{mg} /$ day by day 18 . Prior to clozapine treatment, he had a white blood cell (WBC) count of 9300 cells $/ \mathrm{mm}^{3}$, with $4.0 \%$ eosinophils (absolute count 400 cells $/ \mathrm{mm}^{3}$ ) and $56 \%$ neutrophils (absolute count 51000 cells/ $\mathrm{mm}^{3}$ ). On day 22, the WBC count was 10000 cells $/ \mathrm{mm}^{3}$ with $15.7 \%$ eosinophils $\left(1600\right.$ cells $\left./ \mathrm{mm}^{3}\right)$ and $59.7 \%$ neutrophils $\left(5600\right.$ cells $\left./ \mathrm{mm}^{3}\right)$. On day 27 , the WBC count was 9100 cells $/ \mathrm{mm}^{3}$ with eosinophils increasing to $22.8 \%$ ( 2100 cells/ $\mathrm{mm}^{3}$ ) and neutrophils decreasing to $46.3 \%\left(4100\right.$ cells $\left./ \mathrm{mm}^{3}\right)$. Clozapine was discontinued after consultation with a haematologist and the Department of Veterans Affairs National Clozapine Coordinating Center. Two weeks after the discontinuation of clozapine, the patient had a WBC count of 7300 cells $/ \mathrm{mm}^{3}$ with $18 \%$ eosinophils $\left(1300 \mathrm{cells} / \mathrm{mm}^{3}\right)$ and $36 \%$ neutrophils $\left(2900 \mathrm{cells} / \mathrm{mm}^{3}\right)$. All the blood cell counts returned to normal by eight weeks. Six months later he died from a self-inflicted gun shot wound to the brain while on a combination treatment with loxapine and risperidone.

Eosinophilia may occur in up to 40 $60 \%$ of patients on clozapine and is usually considered transient and asymptomatic (Gerlach et al, 1989, Banov et al, 1993, Bailey, 1997). Cases of symptomatic eosinophilia associated with a decreasing neutrophil count have been reported (Galletley et al, 1996). Sometimes, it acts as a precursor of neutropenia; genetic differences are postulated to explain this variability (Hummer et al, 1996). Current guidelines from the manufacturer recommend discontinuation of clozapine if the eosinophil count goes above 4000 cells/ $\mathrm{mm}^{3}$. Galletley et al (1996) suggest developing guidelines for discontinuation of clozapine in patients with eosinophilia and or decreased neutrophil counts. We believe that eosinophilia is of virtually no clinical utility in predicting clozapine-induced agranulocytosis (Ames et al, 1996; Bailey 1997). Premature discontinuation of 